\title{
Incidence of hip fractures in Salamanca, Spain. Period: 1994-2002
}

\author{
Juan F. Blanco • Agustin Díaz-Alvarez • \\ Jose A. De Pedro • David Borrego • Javier del Pino • \\ Jorge Cortés
}

Received: 21 February 2006 / Accepted: 9 May 2006 / Published online: 7 September 2006

(C) International Osteoporosis Foundation and National Osteoporosis Foundation 2006

\begin{abstract}
Introduction The incidence of hip fractures in Salamanca (Spain) has been lower than in other countries, but has shown a marked increase during the past few decades. The aim of this work is to ascertain the real incidence of hip fractures in the province of Salamanca (Spain) in the period 1994-2002, and based on these results make a prediction for the future (up to the year 2015).

Methods This present study is based on collected data form the discharge register of the University Hospital of Salamanca $(100 \%$ codified) for those patients 65 years of age and older with a diagnosis of hip fracture (ICD-9 820.X) during the period 1994 to 2002 . From this data a descriptive statistical study has been achieved with an analysis covering incidence and the construction of a regression model in order to produce an estimate of fracture incidence up to the year 2015.

Results The number of fractures has practically doubled, with 220 fractures in 1994 and 404 fractures in 2002. The incidence adjusted for age (65 years) shows a very important increase surpassing 315 cases/100,000 (95\% CI: 261-408) in 1994 and rising to 496/100,000 (95\% CI: 388-535) in 2002. The estimate of the incidence for the future tells us that a continuing rise in the increase of hip fracture incidence will occur for the year 2015 with 668/ 100,000 (95\% CI: 516-819).

Conclusions The increase in hip fracture cases is greater than expected due to an aging population, suggesting the

J. F. Blanco $(\bowtie) \cdot$ A. Díaz-Alvarez · J. A. De Pedro •

D. Borrego $\cdot J$. del Pino $\cdot J$. Cortés

Trauma Unit, Facultad de Medicina, Universidad de Salamanca,

Avda. Alfonso x el Sabio,

37007 Salamanca, Spain

e-mail: juanfblanco@telefonica.net
\end{abstract}

existence of other factors influencing this higher incidence. This information should alert the health authorities so they may begin to initiate plans of prevention and management of these very debilitating injuries.

Keywords Hip fracture · Osteoporosis · Incidence

\section{Introduction}

Osteoporosis is an important health problem mainly because of its association with age-related fractures. Osteoporotic hip fractures represent an important cause of morbidity, mortality, and health care costs for the elderly [1, 2]. This has originated the need to establish strategies of prevention and improvement in the management of these patients.

Most studies of the incidence of hip fractures in the world show important geographical variations. The differences are smaller for vertebral fractures. The northern countries (Sweden, Norway) are most affected, in contrast to the lower incidence in southern countries, like Spain [35]. This has probably undervalued this problem in some of these southern countries, resulting in very few health programs that prevent hip fractures. In addition, the incidence of hip fracture increases exponentially with age, especially after age 60 years, and it seems to be generally agreed that the incidence of hip fracture will rise in many countries associated with the aging of populations. Spain is an aging country. Nevertheless the expected increase of incidence of hip fractures in some countries may have stopped [6], which probably would relate to the efforts carried out for the prevention of the hip fractures [7]. 
Previous epidemiological studies in Spain have indicated that incidence of hip fractures is between $301 / 100,000$ and $897 / 100,000$ in patients, 65 years and older. This incidence is lower than that of other countries and with moderate region-to-region variation [8]. In a previous study Ferrandez et al. [9] indicated that the incidence of hip fractures per 100,000 for the age group $>50$ years was 195 for women and 73 for men for the 1977-1988 period in Salamanca. The incidence in our region was one of the lowest in Europe. To establish preventive strategies, it is necessary to know the present and be able to estimate future incidence. A definitive study focused on the evaluation of the estimated incidence in the future has not been conducted in our country. Therefore, the aim of this study is to determine the real incidence of hip fracture in our region in patients aged 65 years or older between 1994 to 2002, and make a prediction for the future incidence and number of hip fractures up to the year 2015, in order to bring to attention this important health problem.

\section{Material and methods}

Spain is an aging country located in southern Europe, with a population greater than 42 million. Salamanca is a province of northwest Spain of 347,120 habitants (2002), with large variations with other regions in Spain.

In Spain, free health care is provided for all people in public hospitals. The University Hospital of Salamanca is the public hospital of Salamanca that attends to $98 \%$ of the population.

\section{Data of fractures}

Using the hospital discharge register (100\% codification) all patients 65 years or older, with the International Classification of Diseases, version 9 (ICD-9), code-class 820.X (hip fracture) from January 1, 1994 through December 31, 2002 have been identified. Data concerning age, sex, type and mechanism of fracture, day of admission, primary and secondaries diagnoses were collected. The cases owing to tumor processes and caused by high energy

Table 1 Analysis of variance of age

\begin{tabular}{llllll}
\hline $\begin{array}{l}\text { Source } \\
\text { variation }\end{array}$ & d.f. & s.s. & m.s. & F & $\begin{array}{l}P \\
\text { value }\end{array}$ \\
\hline Year & 8 & 691,896 & 86,487 & 1.59 & 0.1235 \\
Sex & 1 & 13,047 & 13,047 & 0.24 & 0.6247 \\
Error Exp & 2716 & $148,060,000$ & 54,514 & & \\
Total & 2725 & $148,769,000$ & & & \\
\hline
\end{tabular}

trauma have been excluded. The calculation of incidence is taken from the base population offered by the National Institute of Statistics (INE). The incidence data are expressed in the number of cases per 100,000 inhabitants.

\section{Statistical analysis}

A descriptive study and an estimate of the effect have been carried out, as well as its development in the period. Hip fracture incidences were calculated for both sexes and were expressed as the number of cases per 100,000 people, by gender and age group. We have performed a direct standardization on the basis of the total population of the study period (1994-2002). An estimate of the effect up to 2015 has been done with a model of simple linear regression. The time limit of the year 2015 was chosen to obtain less misleading estimate.

The model of regression used is

$$
Y=\beta_{0}+\beta_{1} X
$$

$Y \quad$ Incidence

$X$ Time in years. $(\mathrm{X}=0,1,2,3,4,5,6,7,8)$

The SPSS 11.0 version, STATGRAPHICS 5.0 and SYSTAT 10.0 packages were used for the statistical analysis.

\section{Results}

In people 65 years and older attending the University Hospital of Salamanca, the total number of hip fractures was 2,726, between 1994-2002. The female/male ratio has been constantly maintained during these years (4/1), and a relative risk of 3 (incidence in people 65 years and older). The average age has also been maintained within a tight

Table 2 Distribution of fractures for year and gender

\begin{tabular}{llllll}
\hline Year & \multicolumn{2}{l}{ Fractures } & & Age & Female/Male (Odds) \\
\cline { 2 - 4 } & Total & Female & Male & & \\
\hline 1994 & 220 & 180 & 40 & 82.6 & $4.50: 1$ \\
1995 & 257 & 205 & 52 & 83.3 & $3.94: 1$ \\
1996 & 274 & 212 & 62 & 83.5 & $3.42: 1$ \\
1997 & 292 & 234 & 58 & 82.9 & $4.03: 1$ \\
1998 & 317 & 243 & 74 & 82.9 & $3.28: 1$ \\
1999 & 293 & 235 & 58 & 83.6 & $4.05: 1$ \\
2000 & 325 & 271 & 54 & 83.5 & $5.02: 1$ \\
2001 & 344 & 284 & 60 & 84.1 & $4.73: 1$ \\
2002 & 404 & 325 & 79 & 83.3 & $4.11: 1$ \\
Total & 2726 & 2189 & 537 & 83.2 & $4.08: 1$ \\
\hline
\end{tabular}




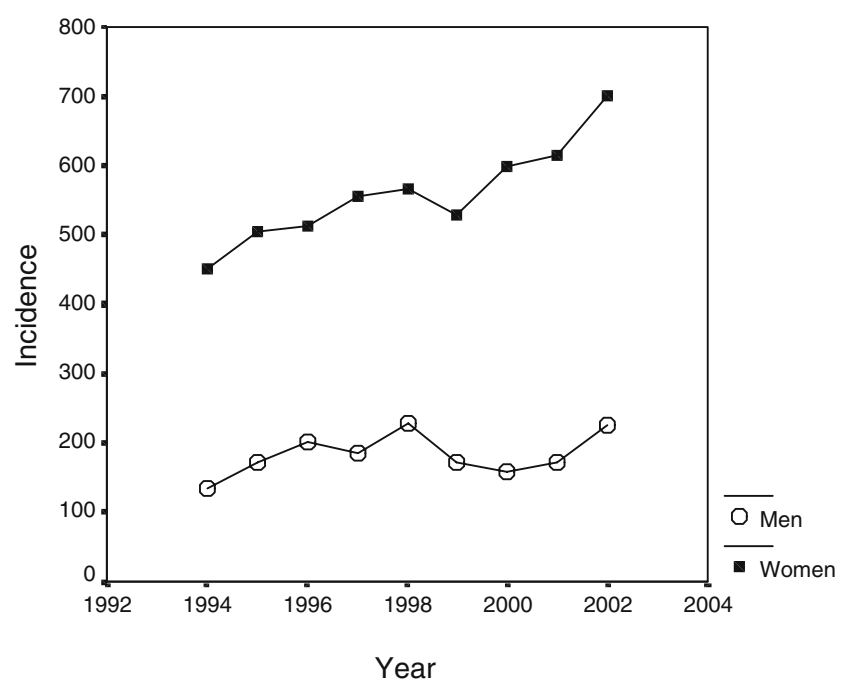

Fig. 1 Incidence of hip fractures in Salamanca in women (triangles) and in men (squares)

range with an average of 83.2 (SD 7.4) years of age (Table 8).

The hip fracture relative increment has been $84 \%$, and the average increase of $9 \%$ per year. The increase was observed in both sexes (Table 2 and Fig. 1), in women and in men, in the year 2002, almost double the fractures observed in the year 1994. This relative increase was $81 \%$ for women and $98 \%$ for men (Tables 3 and 8 ) (Figs. 4 and 5).

The effect has been produced by a notable increase in the incidence, surpassing 315/100,000 (95\% CI: 261-408), 65 years of age and older in 1994 up to 496/100,000 (95\% CI: 388-535) inhabitants 65 years old and up in the year 2002. This increase is not related with the population ageing. During the period 1994-2002, the elderly population 65 years of age and older had a relative increase of $17 \%$ while the relative increase of incidence of hip fractures was $57 \%$, (Table 4) (Fig. 2). The incidence found after the standardization is shown in the Table 5.

The result of the simple regression function is shown in Table 6 and Fig. 3. This analysis indicated that prediction of

Table 3 Incidence in 5-year age bands, for men

\begin{tabular}{llllll}
\hline Year/Age & $65-69$ & $70-74$ & $75-79$ & $80-74$ & $85+$ \\
\hline 1994 & 30 & 75 & 153 & 304 & 394 \\
1995 & 30 & 60 & 169 & 254 & 865 \\
1996 & 20 & 105 & 109 & 484 & 863 \\
1997 & 50 & 80 & 103 & 362 & 838 \\
1998 & 30 & 103 & 241 & 418 & 918 \\
1999 & 68 & 33 & 133 & 315 & 737 \\
2000 & 39 & 44 & 127 & 288 & 699 \\
2001 & 29 & 54 & 122 & 274 & 833 \\
2002 & 49 & 119 & 79 & 300 & 1158 \\
\hline
\end{tabular}

Table 4 Incidence of hip fractures for year

\begin{tabular}{lllll}
\hline Year & Fractures & Total population & $\geq 65$ years & \\
\cline { 4 - 5 } & & & Population & Incidence \\
\hline 1994 & 220 & 355,807 & 69,795 & 315 \\
1995 & 257 & 355,206 & 71,039 & 362 \\
1996 & 274 & 354,304 & 72,288 & 379 \\
1997 & 292 & 353,027 & 73,467 & 398 \\
1998 & 317 & 349,550 & 75,287 & 421 \\
1999 & 293 & 351,128 & 78,054 & 375 \\
2000 & 325 & 349,733 & 79,226 & 410 \\
2001 & 344 & 350,209 & 80,910 & 425 \\
2002 & 404 & 347,120 & 81,531 & 496 \\
\hline
\end{tabular}

the number of fractures for the year 2015 will reach an incidence of 668/100,000 (95\% CI: 516-819) (Fig. 3). These increase represent an enhancement of more than $35 \%$ with respect to the incidence of hip fracture in 2002.

\section{Discussion}

Hip fractures in the elderly population are one of the most important health problems in this age group $[1,2,10]$. There are numerous studies that emphasize the importance of this pathology, and the exponential increase that is produced [11], though some recent studies have also shown a slow levelling off of the increase within various countries either due to lessening in global incidence or statistical variance for one of the two sexes $[6,7,12]$.

Various studies dealing with the incidence of hip fractures in our country are available [13, 14]. Serra et al. [8] have presented a study on the incidence of these types of fractures for the whole of Spain, from data furnished by the central government (Ministry of Consumer and Health), thus contributing data on the incidence in middle-aged citizens, within each region of Spain. Their data referring to our region differs from that found by our studies on the incidence of fractures. Here they are reported an the adjusted rate of 518/100,000 for the period 1996-1999. In

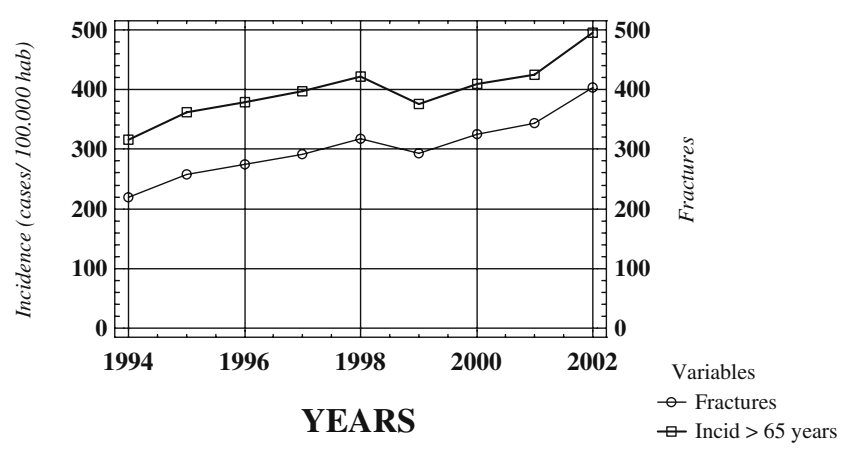

Fig. 2 Incidence and hip fractures in Salamanca 
Table 5 Standardized incidence rate by year and gender

\begin{tabular}{lll}
\hline Year & Men & Women \\
\hline 1994 & 79 & 264 \\
1995 & 101 & 285 \\
1996 & 119 & 293 \\
1997 & 111 & 315 \\
1998 & 133 & 314 \\
1999 & 99 & 289 \\
2000 & 94 & 326 \\
2001 & 100 & 329 \\
2002 & 129 & 326 \\
\hline
\end{tabular}

(Expressed per 100,000 population aged 65 years and older)

our study, the maximum incidence was reached in the year 2002 with 495/100,000 65 years of age and older. This discrepancy could be explained by the different way data were collected. The data recounted by Serra et al. were obtained from the information sent by the hospitals to the central government. There are differences as for the codification between every hospital. On the other hand, we do not know if fractures due to tumor processes or to mechanisms of high energy were excluded. In the case of

Table 6 Incidence estimation of hip fracture (1994-2015)

\begin{tabular}{|c|c|c|c|c|}
\hline \multirow[t]{2}{*}{ Year } & \multirow{2}{*}{$\begin{array}{l}\text { Observed } \\
\text { incidence }\end{array}$} & \multicolumn{3}{|c|}{ Estimated incidence $(95 \% \mathrm{CI})$} \\
\hline & & $\begin{array}{l}\text { Average } \\
\text { estimation }\end{array}$ & $\begin{array}{l}\text { Lower } \\
\text { limit }\end{array}$ & $\begin{array}{l}\text { Upper } \\
\text { limit }\end{array}$ \\
\hline 1994 & 315 & 334 & 261 & 408 \\
\hline 1995 & 362 & 350 & 280 & 420 \\
\hline 1996 & 379 & 366 & 298 & 438 \\
\hline 1997 & 398 & 382 & 316 & 448 \\
\hline 1998 & 421 & 398 & 332 & 464 \\
\hline 1999 & 375 & 414 & 348 & 480 \\
\hline 2000 & 410 & 430 & 362 & 497 \\
\hline 2001 & 425 & 446 & 375 & 516 \\
\hline 2002 & 496 & 461 & 388 & 535 \\
\hline 2003 & & 477 & 400 & 554 \\
\hline 2004 & & 493 & 411 & 575 \\
\hline 2005 & & 509 & 422 & 596 \\
\hline 2006 & & 525 & 433 & 617 \\
\hline 2007 & & 541 & 443 & 639 \\
\hline 2008 & & 557 & 453 & 661 \\
\hline 2009 & & 572 & 462 & 683 \\
\hline 2010 & & 588 & 471 & 705 \\
\hline 2011 & & 604 & 481 & 728 \\
\hline 2012 & & 620 & 489 & 751 \\
\hline 2013 & & 636 & 498 & 773 \\
\hline 2014 & & 652 & 507 & 796 \\
\hline 2015 & & 668 & 516 & 819 \\
\hline
\end{tabular}

Incidence $=334,42+15,86 *$ Time

Time $=0,1,2, \ldots, 22(0=1994)$

$\mathrm{R}^{2}=0,721\left(0 \leq \mathrm{R}^{2} \leq 1\right)$
OBSERVED (1994-2002) AND ESTIMATED (1994-2015) INCIDENCE

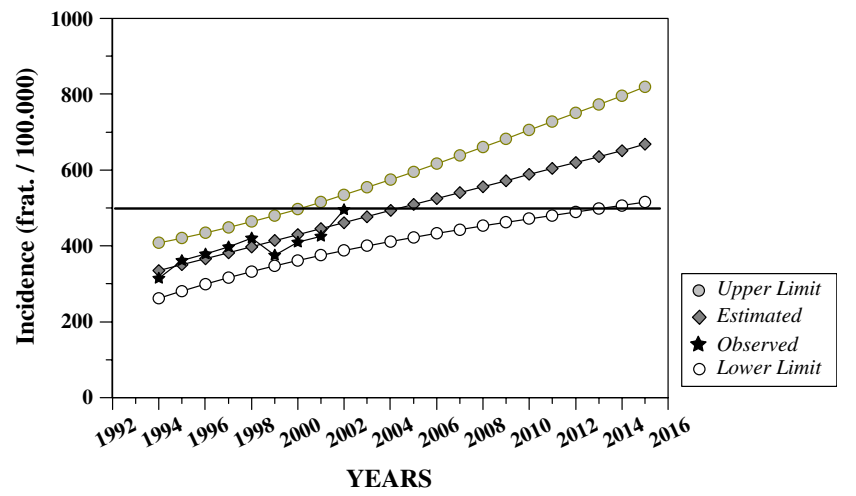

Fig. 3 Observed and estimated incidence, period 1994-2015

the middle-aged group, Serra et al. found evidence for all of Spain at 82 years of age, while in our study it corresponds to 83 years of age. Recently a study on osteoporotic hip fractures in Spain has been available [15]. The hip fracture rate was $694 / 100,000$ in those 60 years and older. The information was obtained at 77 hospitals. The data were requested by the hospitals' departments of orthopedics. There is no information about the origin of the information. This work presents the effect only for the year 2002 .

Other studies on the incidence of hip fractures in various regions of Spain are available, offering general results, for brief periods of time $[13,14,16]$ (Table 7). In agreement with the study by Serra et al. [8], these studies show differences in the incidence, the highest being in northern regions like Barcelona and lower in southern regions like the Canary Islands. This distribution is similar to what is happening in the rest of the world.

Our study clearly shows an important increment in the incidence of hip fractures in the elderly in Salamanca. This increment is more accentuated if we also consider the published data of Ferrandez et al. [9] from our region between 1977-1988. These authors found a total of 1,908 cases of fracture in the elderly (50 years and older), but the incidence of hip fracture in subjects aged under 65 was very low. In our study for the 1994-2002 period, we found 2,726 fractures in the elderly of 65 years of age and older. From 1977 to 1994 the incidence of hip fractures increased 23\%. From 1977 to 2002 the increase in the incidence in older people (65 years and older) was $93 \%$. What this implies is that the increase was dramatically high. The increase is minor when we consider the standardized effect.

The increase in hip fracture cases is greater than expected due to an aging population, suggesting the existence of other factors influencing this higher incidence. What is more, we must assume a progressive increase in the following years with an expectation for the year 2015 of $668 / 100,000$ (95\% CI 516-819) in the elderly population (Figs. 4 and 5, Table 8). 
Table 7 Studies of epidemiology of hip fractures in Spain

\begin{tabular}{lllll}
\hline Author & Period & Location & Age (years) & $\begin{array}{l}\text { Incidence } \\
\text { (female/male) }\end{array}$ \\
$\begin{array}{c}\text { Ferrandez } \\
\text { et al. (1992) }\end{array}$ & $1977-1988$ & Salamanca & 50 & $195 / 73$ \\
$\begin{array}{c}\text { Díez A } \\
\text { et al. (1989) }\end{array}$ & 1984 & Barcelona & 45 & $252 / 115$ \\
$\begin{array}{c}\text { Sosa M } \\
\text { et al. (1993) }\end{array}$ & $1989-1993$ & Canary Islands & 49 & $221 / 170$ \\
$\begin{array}{c}\text { Serra } \\
\text { et al. (2002) }\end{array}$ & $1996-1999$ & Spain & 65 & $695 / 270$ \\
$\begin{array}{c}\text { Herrera A } \\
\text { et al. (2005) }\end{array}$ & 2002 & Spain & 60 & $913 / 417$ \\
$\begin{array}{c}\text { Blanco J } \\
\text { et al. }\end{array}$ & $1994-2002$ & Salamanca & 65 & $699 / 225$ \\
\hline
\end{tabular}

With respect to other European countries, the incidence of hip fractures in our own region is lower than those found in Scandinavian countries [17]. In Belgium, a country situated at a latitude closer to Spain, they have found a substantial increase in the number of fracture cases, reaching an incidence of 108/100,000 in 1984, and 141/100,000 in 1996 [18]. In the case of Greece [19], a country much more similar to Spain and in the south of Europe, the data of fracture incidence found in 1992 is very similar to that found in Spain. The average increase per year (9\%), was close to that observed in Finland (10\%) [20], and bigger than the increase reported in other countries $[19,21]$. The same way, the estimation of incidence in the future (668/ $100,000)$ is similar to the estimation observed by Kannus et al. [20] for Finland $(523 / 100,000)$.

The geographic differences in the incidence of osteoporosis fracture cases are very well known. This research study does not hope to establish the differences

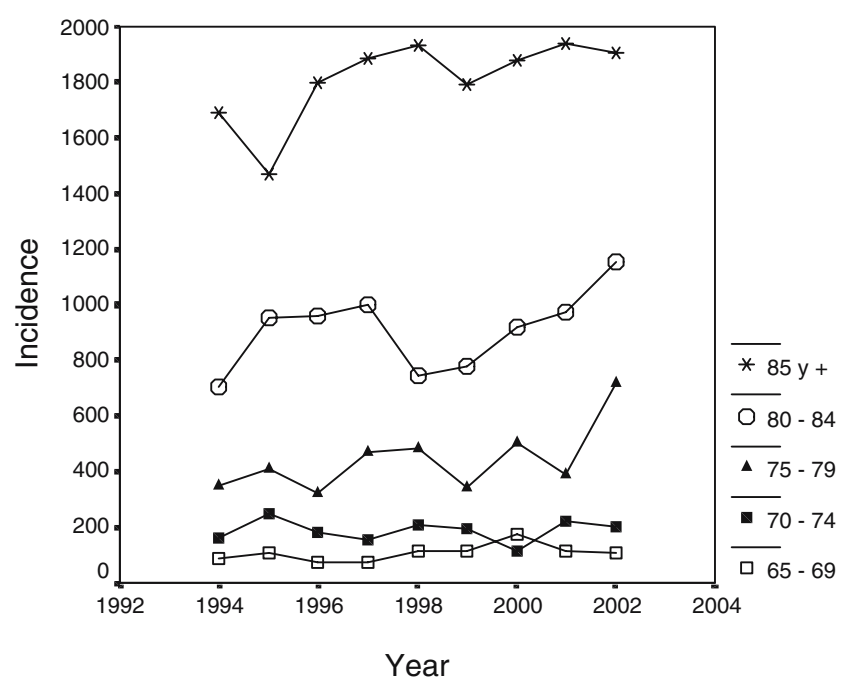

Fig. 4 Incidence of hip fractures in Salamanca in women by age groups concerning the incidence of hip fractures, but more to the point shows these above-mentioned fractures as an important and growing health problem for our country, and that in our region a dramatic increase in hip fracture cases in the past decade has occurred. This new trend will likely continue to increase.

These increases in the incidence of hip fracture in the elderly population should and must motivate health authorities in our country to promote the establishment of innovative and effective measures for the prevention of these geriatric concerns, with prevention programs and quality treatment for osteoporosis, as well as programs to help prevent falling and its subsequent consequences for the elderly. Together with these preventative healthcare measures, in agreement with Herrera et al., we should try to improve the health-watch system of the elderly and to establish useful clinical practice guidelines in the hospitals and extra-hospital care programs that will lead to the obtaining of the best results in social and health terms.

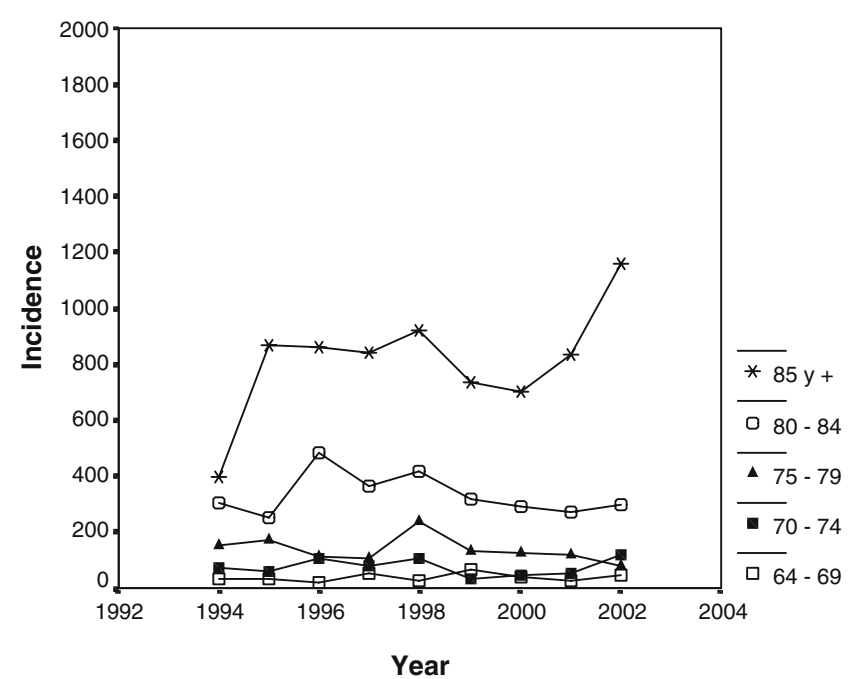

Fig. 5 Incidence of hip fractures in Salamanca in men by age groups 
Table 8 Incidence in 5-year age bands, for women

\begin{tabular}{llllll}
\hline Year/Age & $65-69$ & $70-74$ & $75-79$ & $80-84$ & $85+$ \\
\hline 1994 & 89 & 162 & 347 & 706 & 1691 \\
1995 & 107 & 246 & 407 & 950 & 1472 \\
1996 & 71 & 183 & 323 & 958 & 1797 \\
1997 & 71 & 152 & 472 & 999 & 1882 \\
1998 & 113 & 209 & 484 & 747 & 1930 \\
1999 & 111 & 195 & 344 & 777 & 1789 \\
2000 & 173 & 110 & 500 & 922 & 1877 \\
2001 & 114 & 219 & 391 & 973 & 1937 \\
2002 & 105 & 199 & 716 & 1155 & 1906 \\
\hline
\end{tabular}

\section{Conclusions}

Our study indicates the existence of a very dramatic increase in the incidence of hip fracture in the province of Salamanca, Spain. This increase cannot be explained only by the aging of the elderly population. This information should alert the health authorities to initiate plans of prevention and management of these very debilitating injuries.

\section{References}

1. Johnell O, Kanis JA (2004) An estimate of the worldwide prevalence, mortality and disability associated with hip fracture. Osteoporos Int 15:897-902

2. Melton LJ III (2003) Adverse outcomes of osteoporotic fractures in the general population. J Bone Miner Res 18(6):1139-1141

3. Cummings SR, Melton LJ III (2002) Epidemiology and outcomes of osteoporotic fractures. Lancet 359(18):1761-1767

4. Maghraoui A El, BA Koumba, I Jround, L Achemla, A Bezza, MA Tazi (2004) Epidemiology of hip fractures in 2002 in Rabat, Morocco. Osteoporos Int 28

5. Castro de Rocha FA, Ribeiro AR (2003) Low incidence of hip fractures in an equatorial area. Osteoporos Int 14:496-499
6. Lofthus CM, Osnes EK, Falch JA, Kaastad TS, Kristiansen IS, Nordsletten L, Stensvold I, Meyer HE (2001) Epidemiology of hip fractures in Oslo, Norway. Bone 29(5):413-418

7. Boufous S, Finch CF, Lord SR (2004) Incidence of hip fracture in New South Wales: are our efforts having an effect? MJA 180: 623-626

8. Serra JA, Garrido G, Vidán M, Marañon E, Brañas E, Ortiz J (2002) Epidemiología de la fractura de cadera en ancianos en España. An Med Interna 19(8):389-395

9. Ferrandez L, Hernandez J, Gonzalez-Orus A, Devesa F, Ceinos M (1992) Hip fracture in the elderly in Spain. Acta Orthop Scand 63:386-388

10. Johnell O, Kanis JA, Oden A, Sernbo I, Redlund-Johnell I, Petterson C, De Laet C, Jönsson B (2004) Mortality after osteoporotic fractures. Osteoporos Int 15:38-42

11. Gullberg B, Johnell O, Kanis JA (1997) World-wide projections for hip fracture. Osteoporos Int 7(5):407-413

12. Löfman O, Berglund K, Larsson L, Toss G (2002) Changes in hip fracture epidemiology: Redistribution between ages, genders and fracture types. Osteoporos Int 13:18-25

13. Sosa M, Segarra Mc, Hernández D, Gonzalez A, Liminana JM, Betancor P (1993) Epidemiology of proximal femoral fractures in Gran Canaria (Canary Islands). Age Ageing 22:285-288

14. Díez A, Puig J, Martinez MT, Díez JL, Aubia J, Vivancos J (1989) Epidemiology of fractures of the proximal femur associated with osteoporosis in Barcelona, Spain. Calcif Tissue Int 44:382-386

15. Herrera A, Martínez AA, Ferrandez L, Gil E, Moreno A (2005) Epidemiology of osteoporotic hip fractures in Spain. Int Orthop $18: 1-4$

16. Sánchez MI, Sangrador CO, Blanco IS, Prieto M, Lozano del Valle, Gonzalez TM (1997) Epidemiología de la fractura osteoporótica de cadera en la provincia de Zamora. Rev Esp Salud Publica 71:357367

17. Ismail AA, SR Pye, WC Cockerill et al (2002) Incidence of limb fractrure across Europe: Results from the European prospective osteoporosis study (EPOS). Osteoporos Int 13:565-571

18. Reginster J-Y, Gillet, Gosset C (2001) Secular increase in the incidence of hip fractures in Belgium between 1984 and 1996: need for a concerted public health strategy. Bull World Health Org 79(10):942-946

19. Paspati I, Galanos A, Lyritis GP (1998) Hip fracture epidemiology in Greece during 1977-1992. Calcif Tissue Int 62:542-547

20. Kannus P, Niemi S, Parkkari J, Palvanen M, Vuori I, Jarvinen M (1999) Hip fractures in Finland between 1970-1997 and predictions for the future. Lancet 353(6):802-805

21. Saw LKH, Koh S-M, Lee JJM, Leong KH, Lee J (2001) Hip fracture incidence rates in Singapore 1991-1998. Osteopor Int 12:311-318 